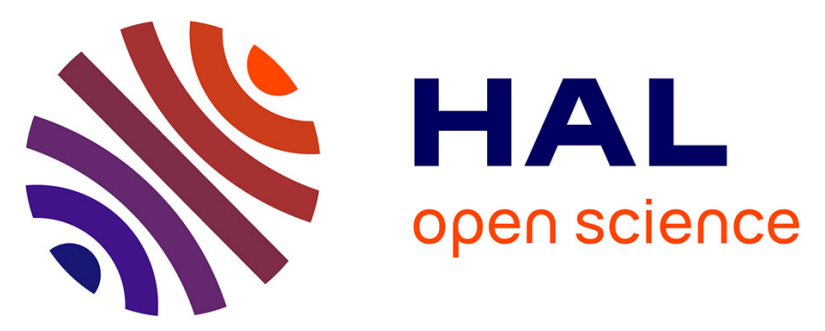

\title{
Autonomous Sensor Node Powered by CM-Scale Benthic Microbial Fuel Cell and Low-Cost and Off-the-Shelf Components
}

T Chailloux, A Capitaine, B Erable, Gaël Pillonnet

\section{- To cite this version:}

T Chailloux, A Capitaine, B Erable, Gaël Pillonnet. Autonomous Sensor Node Powered by CM-Scale Benthic Microbial Fuel Cell and Low-Cost and Off-the-Shelf Components. Energy Harvesting and Systems, 2016, 10.1515/ehs-2015-0030 . hal-01317426

\section{HAL Id: hal-01317426 \\ https://hal.science/hal-01317426}

Submitted on 20 May 2016

HAL is a multi-disciplinary open access archive for the deposit and dissemination of scientific research documents, whether they are published or not. The documents may come from teaching and research institutions in France or abroad, or from public or private research centers.
L'archive ouverte pluridisciplinaire HAL, est destinée au dépôt et à la diffusion de documents scientifiques de niveau recherche, publiés ou non, émanant des établissements d'enseignement et de recherche français ou étrangers, des laboratoires publics ou privés. 


\title{
Autonomous Sensor Node Powered by cm-scale Benthic Microbial Fuel Cell and Low-cost and Off-the-Shelf Components
}

\author{
T. Chailloux ${ }^{1}$, A. Capitaine ${ }^{1}$, B. Erable $^{2}$, G. Pillonnet ${ }^{1}$ \\ ${ }^{1}$ Univ. Grenoble Alpes, F-38000 Grenoble, France \\ CEA, LETI, MINATEC Campus, F-38054 Grenoble, France \\ ${ }^{2}$ Laboratoire de Génie Chimique, CNRS, Université de Toulouse \\ 4 allée Emile Monso, 31029 Toulouse, France.
}

Abstract-Microbial fuel cells (MFC's) are promising energy harvesters to constantly supply energy to sensors deployed in aquatic environments where solar, thermal and vibration sources are inadequate. In order to show the ready-to-use MFC potential as energy scavengers, this paper presents the association of a durable benthic MFC with a few dollars of commercially-available power management units (PMU's) dedicated to other kinds of harvesters. With $20 \mathrm{~cm}^{2}$ of cheap material electrodes, and experimental conditions similar to real ones, $101 \mu \mathrm{W}$ has been generated at $320 \mathrm{mV}$ in steady-state operation. In burst mode, the MFC can generate up to $400 \mu \mathrm{W}$. The PMU, configured to extract the maximum available energy, provides $47 \mu \mathrm{W}$ at $3 \mathrm{~V}$ in steady state, which would allow a wide range of environmental sensors to be powered. A sensor node, consuming $100 \mu \mathrm{J}$ every $4 \mathrm{~s}$ for measurement and wireless transmission of temperature, has been successfully powered by the association of our MFC and the PMU.

Keyword -Microbial Fuel Cell, Energy harvesting, Autonomous sensor node

\section{Introduction}

Harvesting energy from the surrounding environment is an advantageous alternative to conventional batteries for powering autonomous remote sensors. Solar energy, thermal gradient and mechanical vibration are widely used as conventional energy harvesters. However, the microbial fuel cell (MFC), though less studied, is a promising technology that exploits the catalytic properties of bacteria in a few redox reactions, to 
convert chemical energy from sediment into electrical energy. In addition, the field of application is large regarding the wide range of organic substrates that can be used (organic rich sediment, compost, waste water) $[1,2]$. It is also noteworthy that they can be deployed in regions where any other energy harvesters would be inappropriate (seafloors, sewage works). Finally, they can work in a wide range of operating conditions [3] and for a long time [4].

The MFC is a relatively mature technology but the generated power is not directly usable to power low-power sensor nodes continuously. Typically, it generates a few microwatts per square centimeter of electrode, at only a few hundred millivolts. However, different approaches are used to overcome this problem. The first solution consists in stacking several MFCs to have a higher voltage [5] and use a capacitor to store the energy. Another possibility consists in using just one MFC and raising its voltage with switched-mode converters, such as a capacitive converter (charge pump) [6] or inductive converter (boost or flyback converter) [7, 8]. Some researchers propose dedicated circuits to efficiently harvest the MFC energy [9], but these circuits are not directly available for a company which would like to massively deploy this technique in a wide range of applications. The aim of this paper is to demonstrate the efficient association of a low-cost benthic MFC with a commercially-available circuit, designed for other scavenging sources, and to describe the first steps necessary to configure it in order to extract the maximum power from the MFC.

\section{Benthic MFC}

\subsection{MFC elaboration}

A schematic diagram of the MFC is shown in Fig. 1. Bacteria catalyze the oxidation of the organic substrate on the Anode A while the oxygen dissolved in fresh water is reduced at the Cathode $\mathrm{C}$, inducing a transfer of electrons from $\mathrm{A}$ to $\mathrm{C}$ and thus electrical energy generation [1]. Marine sediment was chosen as the anaerobic bacterial medium and as "fuel" (organic matter) in which a thick graphite felt [10] anode is buried. The sediments were collected at $43^{\circ} 04^{\prime} 13.7^{\prime \prime} \mathrm{N}-5^{\circ} 47^{\prime} 37.6$ "E, a beach near a nature conservation area île des Embiez in the Mediterranean Sea. No additional substrate (e.g. acetate) was added for the start-up phase or during steady-state operation, in order to mimic natural conditions. Based on previous work on another MFC and substrate [11], we estimated the volume of the anode $\left(20 \mathrm{~cm}^{2} \times 1 \mathrm{~cm}\right)$ to generate around $200 \mu \mathrm{W}$. Then, a $20 \mathrm{~cm}^{2}$, thick graphite felt cathode was placed in artificial seawater. Electrons were collected from the electrodes by $\varnothing 0.75 \mathrm{~mm}$ insulated titanium wires. Although titanium 
is not the best electrical conductor available, it was chosen because of its high resistance to corrosion mainly due to the oxide passivation layer formed on its surface $\left(\mathrm{TiO}_{2}\right)$. It is also less rare and less expensive than platinum. We used the setup according to [12] as the MFC is being used for more than 4 months.

The material for each fuel cell cost only a few dollars, so many MFCs could be scattered in oceans and lakes, and a large matrix of self-sufficient sensor nodes could thus be deployed all around the world.

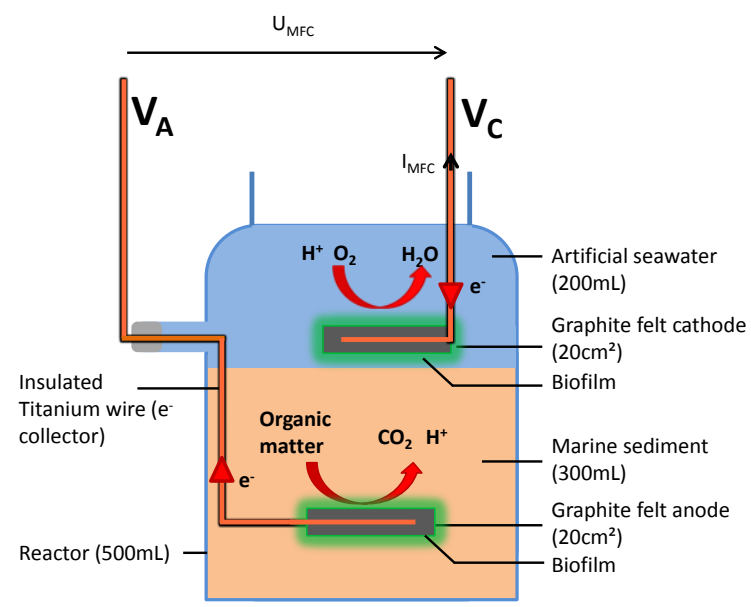

Figure 1: Schematic diagram of the in-situ MFC

\subsection{MFC electrical characterization}

As we intend to use the MFC for long-term energy generation, it needs to be characterized in steady state, meaning that each operating point must be stable for a long time before recording the current and voltage. If the sweep is too fast, the MFC characteristic could be biased by capacitive effects [13] and thus its performance over-estimated for our steady-state electrical generation. The MFC characteristics found in most of the literature are obtained with fast sweeps [14] and therefore only give an order of magnitude of the power available for long-term generation.

The green curve in Fig. 2 shows a static characterization of the MFC (current $I_{M F C}$ $\mathrm{v}$ voltage $\left.U_{M F C}=V_{C^{-}} V_{A}\right)$. $U_{M F C}$ was set step by step, while $I_{M F C}$ was measured in real time. The current always starts with a peak value, and then slowly decreases. Both $I_{M F C}$ and $U_{M F C}$ were recorded when steady-state was achieved, which occurred after at least 10 minutes. The average sweep speed is $33 \mu \mathrm{V} / \mathrm{s}$. The overall U-I curve is thus obtained after about 3 hours. 
The open-circuit voltage, $U_{M F C_{-} O C}$, is $510 \mathrm{mV}$, confirming the need for a harvesting interface to ultimately power sensors or actuators. In short-circuit conditions, the MFC delivers $480 \mu \mathrm{A}$. The blue curve in Fig. 2 also shows the calculated power $U_{M F C} \times I_{M F C} \mathrm{~V}$ $U_{M F C}$. The maximum power point (MPP) is achieved at $U_{M F C}=320 \mathrm{mV}$. At this point, the harvested power is $101 \mu \mathrm{W}$ corresponding to a power density of $50.5 \mathrm{~mW} / \mathrm{m}^{2}$, considering a $20 \mathrm{~cm}^{2}$ anode surface. The MFC was also characterized with a voltage rate sweep of $10 \mathrm{mV} / \mathrm{s}$ (300 times faster than the previous characterization) and a maximum power of $401 \mu \mathrm{W}$ was measured, underlining the over-estimation of this procedure. Although these results are below the state-of-the-art ones and below our first estimation, it is worth mentioning two points. First, it is a steady-state performance, and second, no additional substrate (e.g. acetate) was used to boost the MFC start-up or its normal operation. Therefore, the data given here are the closest to the long-term generation capabilities of MFC's in a natural environment.

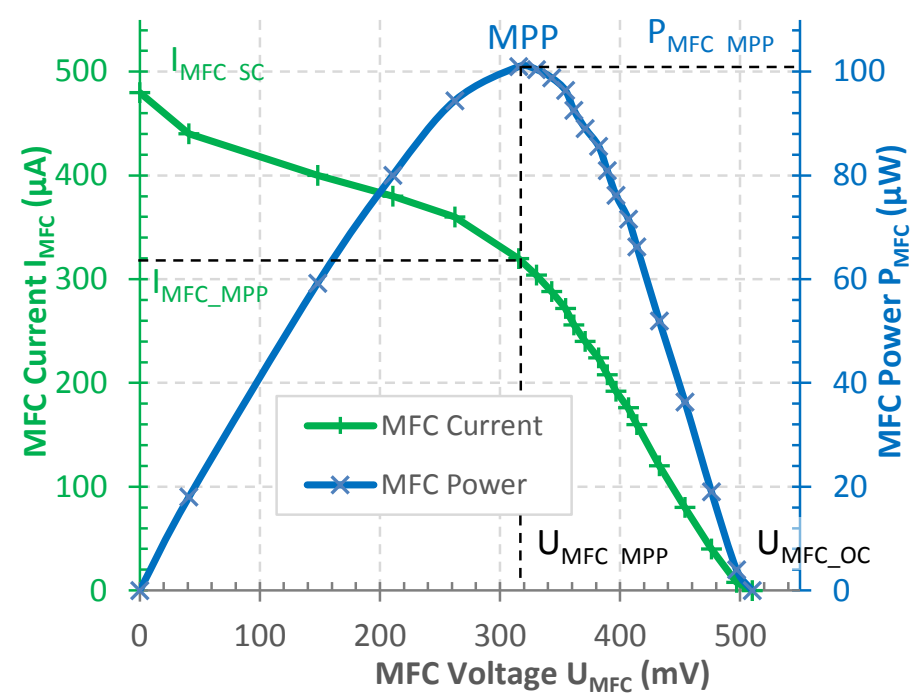

Figure 2: Static polarization curve of the MFC measured by varying the MFC output voltage by steps at $33 \mu \mathrm{V} / \mathrm{s}$ (green curve). Output power (blue curve) 


\section{Power Management Unit (PMU)}

\subsection{PMU characterization}

A commercial integrated circuit for scavenging sources, like photovoltaic or thermal electric generators, has been used as a PMU [15] and configured to meet our specifications. The role of the PMU is to ultimately interface the low voltage generated by the MFC with the energy storage intermittently supplying a sensor node. It was chosen because of its low voltage $(\geq 100 \mathrm{mV})$ and low power $(\geq 5 \mu \mathrm{W})$ capabilities, and because of its low leakage current. A PMU basically consists of a high efficiency boost converter to raise the voltage, extract maximum power and store energy in a storage element (capacitor and/or battery). A boost converter is an electrical device that steps up the input voltage. In addition, it can adapt its impedance to reach the maximum power extraction. Since the control logic of this converter needs a minimal voltage to operate (typically $>0.5 \mathrm{~V}$ ), the circuit also needs either an external voltage source (non-autonomous solution) or an auxiliary start-up circuit to initially step the voltage up to $1.8 \mathrm{~V}$. This is called cold-start and this low efficiency ultra-low voltage step-up conversion is typically performed by a charge pump [16] or, as in the circuit used here, an unregulated boost converter.

In order to measure the efficiency of the PMU close to MFC operating points, the main boost converter has been electrically characterized. For this, two Keithley 2401 SMU's were used as the power source and power sink (load), respectively, and a Keysight E3640A voltage source to set an external reference voltage for the input voltage, the PMU deciding on the right duty cycle (Fig. 3).

Voltage and current ranges were chosen according to the MFC characteristics. Since the MFC maximum voltage is $510 \mathrm{mV}$ and the voltage at the MPP is $320 \mathrm{mV}$, the input voltage of the PMU was set between $50 \mathrm{mV}$ and $500 \mathrm{mV}$, with finer steps around $300 \mathrm{mV}$. The current was set from $25 \mu \mathrm{A}$ to $1500 \mu \mathrm{A}$. The output voltage was set at $3 \mathrm{~V}$ to match a large range of sensors and actuators, especially for the sensor node used in the next section. The measurements have been done after the PMU has started, since the cold start circuit on chip requires $340 \mathrm{mV}$ to start. Results are shown in Fig. 4 and match those of the PMU datasheet [15] very well. At $U_{i n}=320 \mathrm{mV}$ and $I_{i n}=320 \mu \mathrm{A}$, corresponding to the MFC MPP, the PMU efficiency is around $70 \%$, and therefore seems suitable for our power source. 


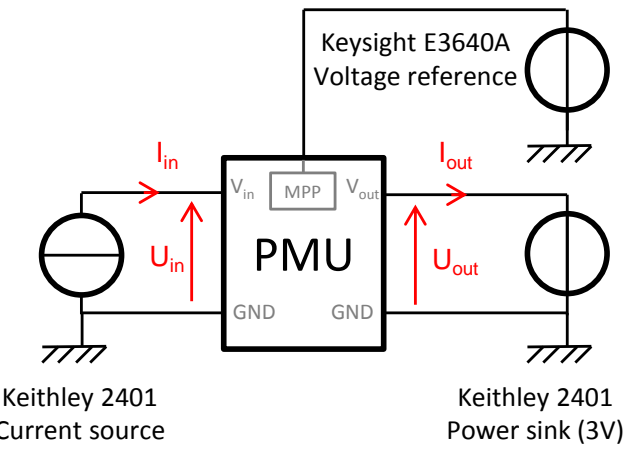

Figure 3: Schematic of the experimental setup used to characterize the PMU.

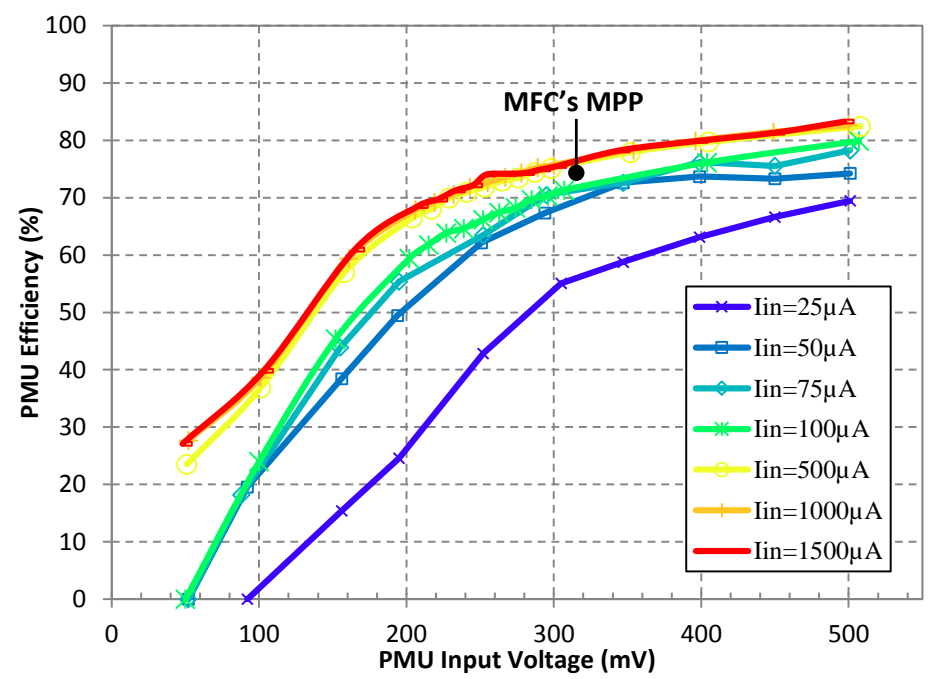

Figure 4: Efficiency of the PMU under test in the MFC operating range

At low input power, however, the efficiency of the PMU is low because the switching losses and control logic consumption are significant compared to the input power.

For the above converter, it is interesting to note that it is best to work with an input current greater than $50 \mu \mathrm{A}$, but increasing the input current further will not lead to any major increase in the converter efficiency, whereas increasing the voltage will. 


\subsection{MPP Tracking}

In autonomous operation, no external reference voltage is available to set the MPP. Instead, the MPP tracking (MPPT) is based on setting the PMU input voltage to a fraction of the input voltage in open circuit. Every 16 seconds, the PMU stops its operation and the open-circuit input voltage is measured after $256 \mathrm{~ms}$. The fraction of the opencircuit voltage is set by a customizable resistive voltage [15] and so the PMU does not need an external reference. However, this setup cannot be used as is because the order of magnitude of the MFC time constant is much higher than the measurement time (some ten seconds). As the measurement time for the open-circuit voltage is internally set and cannot be tuned, the open-circuit voltage cannot be measured directly. However, an adaptation of this MPPT method is still possible to meet our specifications.

Based on our observations, we will consider the MFC as a first-order system with a time constant $\tau$. Just before the $256 \mathrm{~ms}$ rest time, the MFC voltage is set at $U_{n}$. $U_{M F C_{-} O C \text {, }}$ the MFC open-circuit voltage; this varies sufficiently slowly compared to the MPPT algorithm that it can be considered constant. After resting for $256 \mathrm{~ms}$, the voltage will increase as a first-order response (Fig. 5). Thus, $U_{\text {rest }}$, the MFC voltage after $t_{\text {rest }}=$ $256 \mathrm{~ms}$, is given by (2).

$$
U_{\text {rest }}=\left(U_{M F C_{-} o c}-U_{n}\right)\left(1-\exp \left(-\frac{t_{\text {rest }}}{\tau}\right)\right)+U_{n}
$$

The PMU then sets the next MFC voltage to a fraction of $U_{\text {rest }}$ measured with a resistive voltage divider (3). The MFC voltage $\left(U_{n}\right)$ follows a sequence defined by recursion (4) and will converge to $U_{\text {limit }}(5)$ after several iterations (Fig. 5).

$$
\begin{aligned}
U_{n+1} & =\frac{R_{2}}{R_{1}+R_{2}} U_{\text {rest }}=\alpha \cdot U_{\text {rest }} \\
U_{n+1} & =\alpha \cdot K \cdot U_{M F C_{-} O C}+\alpha \cdot(1-K) \cdot U_{n} \text { avec } K=1-\exp \left(-\frac{t_{\text {rest }}}{\tau}\right) \\
U_{\text {limit }} & =\frac{\alpha \cdot K}{1+\alpha \cdot K-\alpha} U_{M F C_{-} O C}
\end{aligned}
$$

Under the assumption that the MFC time constant does not change and is accurately measured (12.740s in this case), $K$ is constant and $U_{\text {limit }}$ can be controlled and fixed as a fraction of the open-circuit voltage by calculating the proper $\alpha$, by choosing the right resistance ratio. Given the characteristics of our MFC, the MPP is achieved at $60-65 \%$ of the open-circuit voltage $U_{M F C_{-}} O C$.

If $U_{M F C_{-} O C}$ varies over time, the set point will auto-adjust, so a dynamic MPPT is autonomously achieved. 


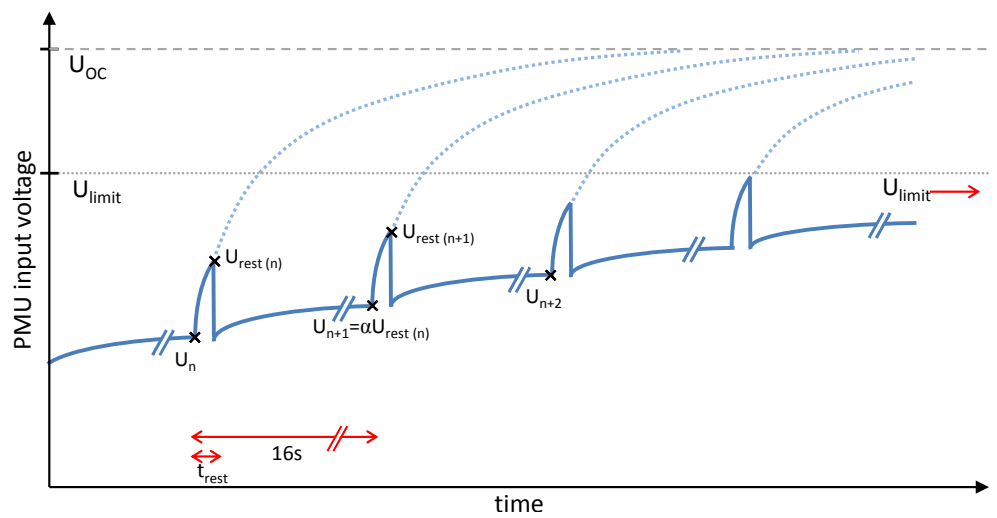

Figure 5: MPPT operation. Evolution of the PMU input voltage to reach the target $\mathrm{U}_{\text {limit }}$

\section{MFC and PMU association}

\subsection{Electrical characterization and optimization}

The MFC was connected to the previously characterized PMU as a power source and a $3 \mathrm{~V}$ power sink (Keithley 2401) was used as a load (Fig. 6). Equations (6) express this coupling. By using an external reference (supplying less than $100 \mathrm{pW}$ to the PMU) and setting it from 0 to $510 \mathrm{mV}$, the average input voltage was also controlled, in order to change the operating point of the MFC at will. Thus, the extracted power at a specific operating point is related to the available MFC power $\mathrm{P}_{\mathrm{MFC}}$ and the PMU efficiency $\eta$ given by equation (7).

$$
\begin{aligned}
& \left\{\begin{array}{l}
U_{i n}=U_{M F C} \\
I_{\text {in }}=I_{M F C}=f\left(U_{M F C}\right)
\end{array}\right. \\
& P_{M F C+P M U}=P_{M F C}\left(U_{M F C}\right) \cdot \eta_{P M U}\left(U_{i n} ; I_{i n}\right)
\end{aligned}
$$

The extracted power dissipated in the load (dashed blue curve in Fig. 7) can be compared to the raw power of the MFC (solid blue curve) shown previously in Fig. 2. The red curve represents the efficiency of the PMU. The maximum extracted power is $47 \mu \mathrm{W}$ and it is achieved at an input PMU voltage of $340 \mathrm{mV}$. At this optimum, the efficiency of the converter is 57\%. This global MPP resulted from a compromise between the maximum power supplied by the MFC around $\mathrm{U}_{\mathrm{MFC}}=320 \mathrm{mV}$ (Fig. 2) and the increasing efficiency with rising $\mathrm{U}_{\text {in }}$ (Fig. 4). 


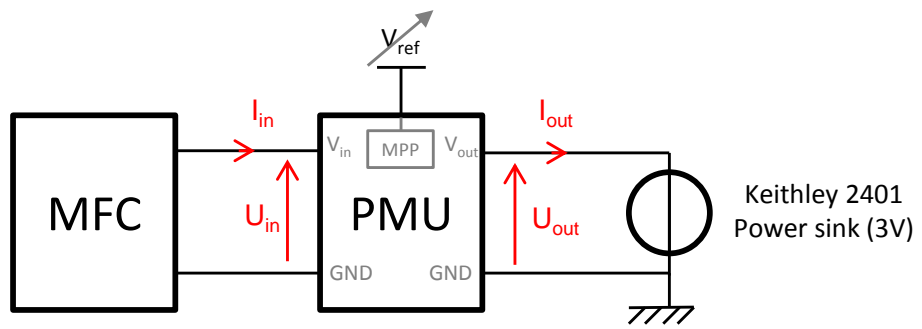

Figure 6: The experimental setup used to characterize the MFC and PMU association.

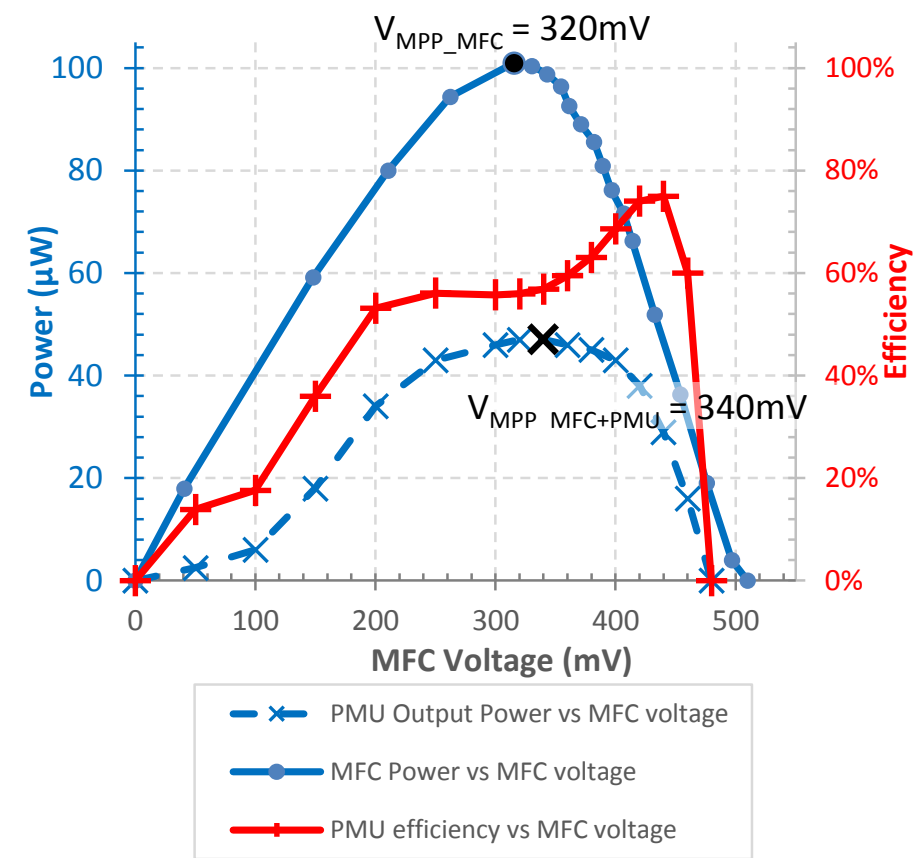

Figure 7. Power and efficiency curves: MFC output power (solid blue curve), PMU extracted power (dashed blue curve) and PMU efficiency (red curve).

\subsection{Powering a sensor node}

Since the association of the MFC and PMU is able to generate $47 \mu \mathrm{W}$ in steady state, we experimented on their association with a low-power sensor node, for measur- 
ing useful data in a seafloor environment (Fig. 8). The sensor node used in our experiment [17] is able to sense temperature and acceleration to predict algae and seismic events, respectively. The sensor is also able to communicate with a $2.4 \mathrm{GHz}$ Bluetooth Low Energy wireless protocol [18]. It is configured to wake up its operation when supplied with at least $3 \mathrm{~V}$, and to operate with at least $1.8 \mathrm{~V}$. The energy consumption of the sensor node is about $340 \mu \mathrm{J}$ to wake-up and $100 \mu \mathrm{J}$ for each sensing cycle (including sensing, processing and wireless data emission). Assuming that about $47 \mu \mathrm{W}$ can be extracted from an MFC the minimum period for transmitting data is around $2 \mathrm{~s}$.

Waking up the sensor is the most critical condition for choosing the value of the energy storage capacitor. Assuming the maximum required energy is $340 \mu \mathrm{J}$ the wakeup voltage $3 \mathrm{~V}$ and the minimum supply voltage $1.8 \mathrm{~V}$, then the capacitor value has to be greater than $118 \mu \mathrm{F}$. For our application, the harvested energy was continuously stored in a $220 \mu \mathrm{F} 6.3 \mathrm{~V}$ aluminum electrolytic capacitor [19] and was intermittently extracted to power the sensor node (Fig. 9).

The sensor was configured to transmit data every 4 seconds, requiring an average power consumption of $25 \mu \mathrm{W}$. In this configuration, the sensor node was successfully detected and paired with a smartphone and data transmitted (acceleration and temperature measurements) (Fig. 9 and Fig. 10). With an antenna emerging from the water, this cheap setup could be used on the coastline to monitor the water temperature in longterm operation.

The association of an MFC and PMU could be used with the same efficiency to power a more energy-consuming sensor. For example, a sensor requiring at most $1 \mathrm{~mJ}$ could be used at least every $21.3 \mathrm{~s}$. Considering the same voltage constraints as above, the capacitor value should be higher than $354 \mu \mathrm{F}$. Depending on the technology of the energy storage element (electrolytic capacitor, supercapacitor or lithium battery, etc., the leakage current and equivalent series resistor would be different and would therefore affect the storage efficiency.

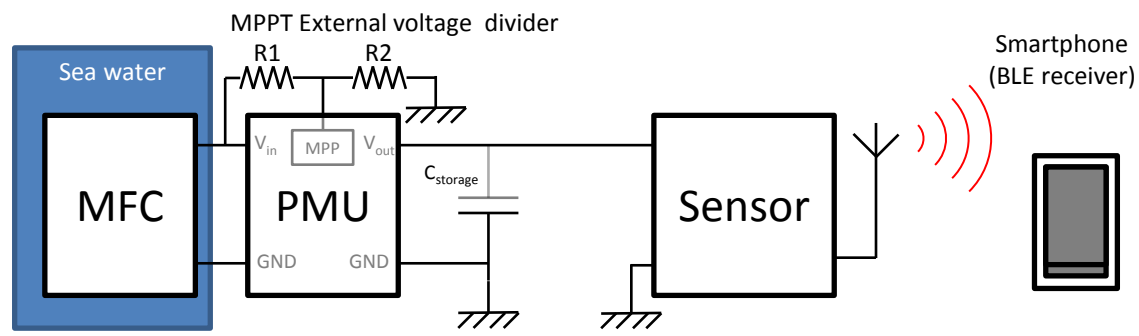

Figure 8: The experimental setup used to power the sensor with the MFC and PMU. 


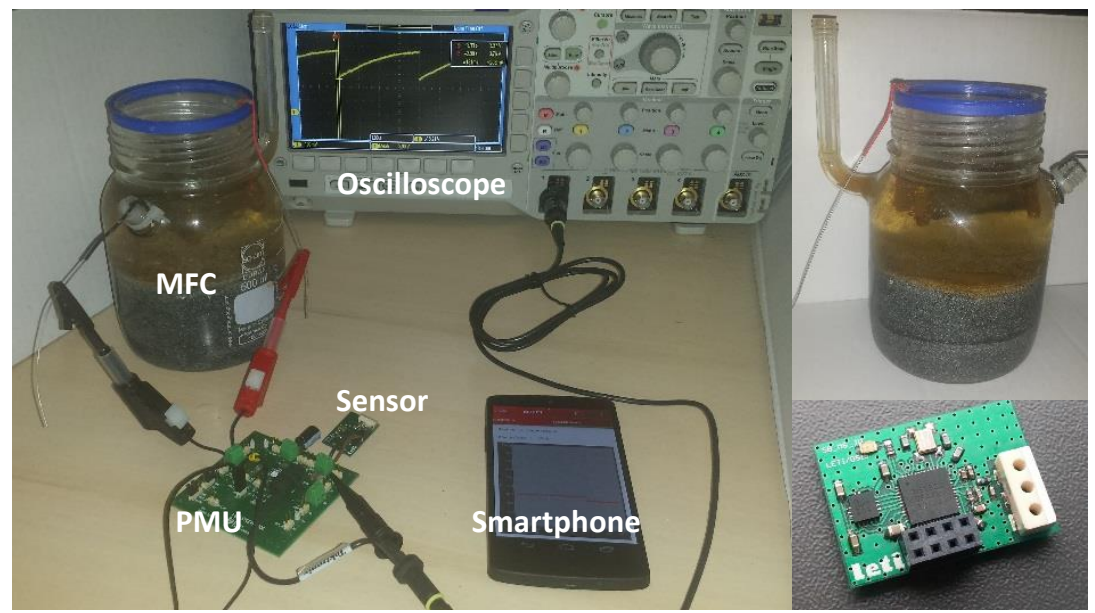

Figure 9: Left: Experimental setup with the MFC, PMU, sensor node, a smartphone (BLE receptor) and oscilloscope. Top right: Microbial Fuel Cell. Bottom right: Sensor node.

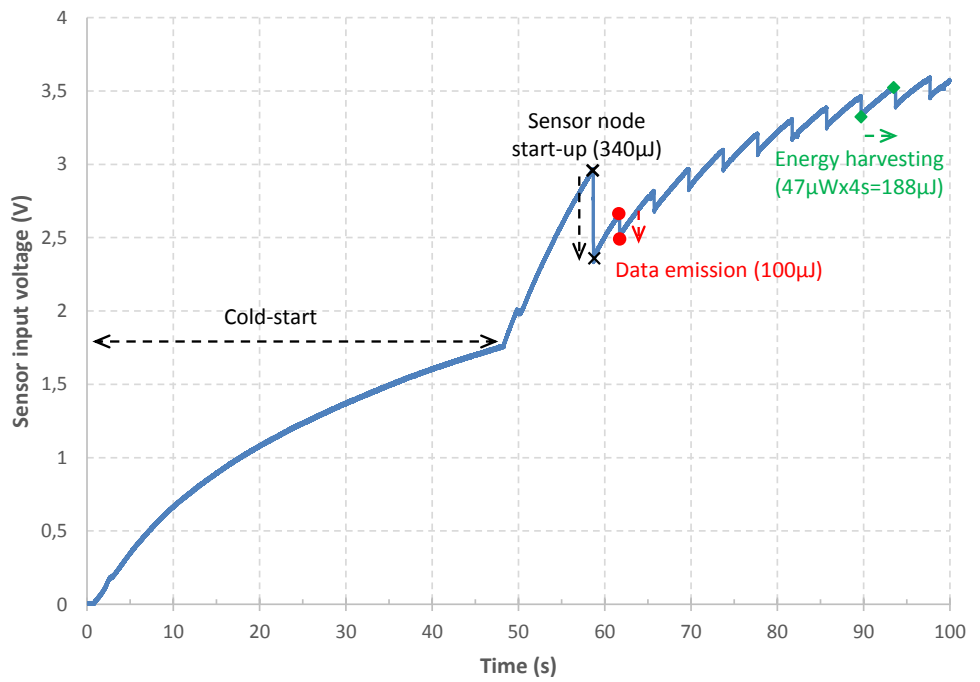

Figure 10: Measurement of the sensor node input voltage. 


\section{Conclusion}

In this paper, a sensor node has been successfully powered by the energy harvested from a centimeter-scale, cheap and close-to-real-conditions microbial fuel cell (MFC), using a commercially-available harvesting interface. The MFC and power management unit have been thoroughly characterized separately in order to show their compatibility with our specifications. Their association allows the optimal operating point to be chosen to dynamically maximize the overall power extraction.

The harvested energy was continuously stored in a capacitor. This energy could be used to power a sensor and intermittently transmit data using wireless communication. An adaptation of the maximum power point tracking (MPPT) of the PMU has been proposed to deal with the slow dynamic of the MFC.

Our future work will focus on rethinking the power management strategy, then optimizing the MPPT, and finally designing a customized PMU IC for sediment microbial fuel cells.

\section{Acknowledgment}

We would like to thank Sebastien Boisseau, Pierre Gasnier and Jerome Willemin from CEA LETI (Grenoble, France) for their sensor node design and helpful advice for testing it. We would also like to thank Alain Bergel from Laboratoire de Génie Chimique (Toulouse, France) for his collaboration on the MFC elaboration. Finally, we would like to thank Wafa Achouak and Oulfat Amin Ali from the Laboratory of Microbial Ecology of the Rhizosphere and Extreme Environment (LEMiRE) for their help on MFC characterization.

\section{References}

[1] Kiran V., Gaur B. (2013): Microbial Fuel Cell: technology for harvesting energy from biomass, Reviews in Chemical Engineering. Volume 29, Issue 4, Pages 189-203, Aug. 2013.

[2] Venkata Mohan S., Velvizhi G., Annie Modestra J., Srikanth S. (2014): Microbial fuel cell: Critical factors regulating bio-catalyzed electrochemical process and recent advancements, Renewable and Sustainable Energy Reviews, Dec. 2014.

[3] Jadhav G.S., Ghangrekar M.M. (2009): Performance of microbial fuel cell subjected to variation in $\mathrm{pH}$, temperature, external lad and substrate concentration, Bioresource Technology, Volume 100, Issue 2, pp 717-723, Jan. 2009. 
[4] Sevda S., Dominguez-Benetton X., Graichen F.H.M., Vanbroekhoven K., Wever H.D., Sreekrishnan T.R., Pant D. (2016): Shift to continuous operation of an air-cathode microbial fuel cell longrunning in fed-batch mode boosts power generation, International Journal of Green Energy, Volume 13, Issue 1, Pages 71-79, Jan. 2016.

[5] Aelterman P., Rabaey K., Pham H.T., Boon N., Verstraete W. (2006): Continuous Electricity Generation at high voltages and currents using stacked Microbial Fuel Cells, Environmental Science and Technology, Volume 40, Issue 10, pp 3388-3394, Apr. 2006.

[6] Lee I., Kim G., Bang S., Wolfe A., Bell R., Jeong S., Kim Y., Kagan J., Arias-Thode M., Chadwick B., Sylvester D., Blaauw D., Lee Y. (2015): System-On-Mud: Ultra-Low Power Oceanic Sensing Platform Powered by Small-Scale Benthic Microbial Fuel Cells, IEEE Transactions on Circuits and systems, Volume 62, No. 4, Apr. 2015.

[7] Khaled F., Allard B., Ondel O., Vollaire C. (2015): Autonomous Flyback Converter for Energy Harvesting from Microbial Fuel Cells, Energy Harvesting and Systems, Nov. 2015

[8] Capitaine A., Pillonnet G., Chailloux T., Khalel F., Ondel O., Allard B. (2016): Loss Analysis of Flyback in Dicontinuous Conduction Mode for sub-mW Harvesting Systems, Proceedings of New Circuits and Systems Conference (NEWCAS), 2016 IEEE 14th International, 2016.

[9] Wang H., Park J-D., Ren Z.J. (2015): Practical Energy Harvesting for Microbial Fuel Cells: A review, Environmental Science \& Technology, vol. 49, pp. 3267-3277, Mar. 2015.

[10] Datasheet of MERSEN RVG4000 graphite felt.

[11] Capitaine A., Chailloux T. (2015): Electrical characterization and modeling of benthic microbial fuel cells for energy harvesting, Proceedings of JNRSE 2015, 2015.

[12] Erable B., Lacroix R., Etcheverry L., Féron D., Delia M.L., Bergel A. (2013): Marine floating microbial fuel cell involving aerobic biofilm on stainless steel cathodes, Bioresource Technology, Aug. 2013.

[13] Sevda S., Chayambuka K., Sreekrishnan T.R., Pant D., Dominguez-Benetton X. (2015): A comprehensive impedance journey to continuous microbial fuel cells, Bioelectrochemistry, Special Issue on "Biological fuel cells", Volume 106, Part A, Pages 159-166, Dec. 2015.

[14] Guerrini E., Grattieri M., Faggianelli A., Cristiani P., Trasatti S. (2015): PTFE effect on the electrocatalysis of the oxygen reduction reaction in membraneless microbial fuel cells, Bioelectrochemistry, Volume 106, Pp 240-247, Dec. 2015.

[15] Datasheet of Texas Instruments BQ25570 Ultra Low Power Harvester Power Management IC with Boost Charger, and Nanopower Buck Converter.

[16] Pillonnet G., Martinez T. (2015): Sub-threshold startup charge pump using depletion MOSFET for a low-voltage harvesting application, Energy Conversion Congress and Exposition (ECCE 2015) IEEE, pp 3143-3147, 2015.

[17] Perez M., Boisseau S., Gasnier P., Willemin J., Pourchier N., Geisler M., Reboud J.L. (2015): Electret-based aeroelastic harvester and its self-starting battery-free power management circuit, New Circuits and Systems Conference (NEWCAS), 2015 IEEE 13th International, pp 1-4, 2015.

[18] Datasheet of Nordic Semiconductor nRF51 ultra-low power System-On-Chip.

[19] Datasheet of Rubycon 6.3YXJ220M5X11 Miniature Aluminum Electrolytic Capacitors. 